\title{
Graphene-based materials for the catalytic wet peroxide oxidation of highly concentrated 4-nitrophenol solutions
}

Rui S. Ribeiro ${ }^{\mathrm{a}}$, Adrián M.T. Silva ${ }^{\mathrm{b}}$, Luisa M. Pastrana-Martínez ${ }^{\mathrm{b}}$, José L. Figueiredo ${ }^{\mathrm{b}}$, Joaquim L. Faria ${ }^{\mathrm{b}}$, Helder T. Gomes ${ }^{\mathrm{a}}$ *

LCM - Laboratory of Catalysis and Materials - Associate Laboratory LSRE/LCM.

a Department of Chemical and Biological Technology, School of Technology and Management, Polytechnic Institute of Bragança, Campus de Santa Apolónia, 5300-857 Bragança, Portugal.

${ }^{b}$ Department of Chemical Engineering, Faculty of Engineering, University of Porto, Rua Dr. Roberto Frias, 4200-465 Porto, Portugal.

*Corresponding author. Tel.: +351 273303 110; Fax: +351273 313051.

E-mail address: htgomes@ipb.pt 


\section{Abstract}

Reduced graphene oxide (rGO) samples were prepared from graphene oxide (GO) using different reducing agents (i.e., glucose, hydrazine and vitamin $\mathrm{C}$, resulting in $\mathrm{rGOG}, \mathrm{rGOH}$ and rGOV, respectively). These samples were tested in the catalytic wet peroxide oxidation (CWPO) of highly concentrated 4-nitrophenol (4-NP) solutions $\left(5 \mathrm{~g} \mathrm{~L}^{-1}\right)$ at mild operating conditions (i.e., atmospheric pressure, $T=323 \mathrm{~K}, \mathrm{pH}=3$, [catalyst] $=2.5 \mathrm{~g} \mathrm{~L}^{-1}$ and $\left.\left[\mathrm{H}_{2} \mathrm{O}_{2}\right]_{0}=17.8 \mathrm{~g} \mathrm{~L}^{-1}\right)$. The highest catalytic activity was found for the rGOV sample, reaching a 4-NP removal of $1294 \mathrm{mg} \mathrm{g}^{-1}$ and a TOC removal of $241 \mathrm{mg} \mathrm{g}^{-1}$ after $24 \mathrm{~h}$ runs (corresponding to 4-NP and TOC removals of $65 \%$ and $23 \%$, respectively).

The TOC removal per unit of $\mathrm{H}_{2} \mathrm{O}_{2}$ decomposed decreases with the increase of the surface oxygen content of the samples, as well as with the increase of their amounts of structural defects. This was ascribed, respectively, to the electron withdrawal capacity of oxygencontaining functionalities and to reduced adsorption of 4-NP in the samples with higher amount of defects, which diminish the efficiency of the reaction between hydroxyl radicals resulting from the decomposition of $\mathrm{H}_{2} \mathrm{O}_{2}$ and the organic compounds.

In a series of three consecutive CWPO runs, $\mathrm{rGOH}$ was the most stable material (4-NP removal slightly decreasing from $980 \mathrm{mg} \mathrm{g}^{-1}$, in the first and second runs, to $841 \mathrm{mg} \mathrm{g}^{-1}$ in the third run, corresponding to $4-\mathrm{NP}$ removals of $49 \%$ and $42 \%$, respectively). The development of oxygen functionalities at the surface of the rGO samples during the CWPO runs was found to be the major cause of catalyst deactivation.

4-Nitrocatechol was the main aromatic intermediate detected in the CWPO of 4-NP. Hydroquinone, benzoquinone, catechol and several low molecular weight carboxylic acids (e.g. malonic, malic, maleic and acetic acids) were also identified as reaction intermediates.

To the best of our knowledge, graphene-based materials are reported for the first time as active and stable catalysts in the CWPO process, even when applied to highly polluted waters at mild conditions. 
Keywords: Graphene-based materials; Reduced graphene oxide; Catalytic wet peroxide oxidation (CWPO); Highly polluted waters; 4-Nitrophenol. 


\section{Introduction}

Graphene and its derivatives possess unique electronic, optical, thermal and mechanical properties, in addition to large theoretical specific surface areas and high adsorption capacities [1-3]. Graphene properties fascinated the scientific community, as recognized by a Nobel Prize in 2010. This two-dimensional honeycomb lattice, formed by hexagonally arrayed $s p^{2}$-bonded carbon atoms, can be considered as the basic building block for all other dimensionalities: 0D buckyballs, 1D nanotubes or 3D graphite [1, 4]. Specifically, it is known that the strong $\sigma$ bonds work as the rigid backbone of the $2 \mathrm{D}$ honeycomb graphene structure, whereas the out-of plane $\pi$ bonds control the interaction between the graphene sheets, allowing delocalized $\pi$ electrons to be easily conducted through the basal plane [1].

Graphene is a very promising nanostructure in several technological applications [1]. Nevertheless, it still suffers from a typical problem of many novel materials: the lack of well established synthesis processes for large scale production [1]. One of the most popular and developed ways to produce graphene-based materials consists of the initial strong chemical oxidation of natural graphite to graphite oxide, followed by mechanical, chemical or thermal exfoliation of graphite oxide to graphene oxide (GO) sheets, which are finally chemically reduced, resulting in reduced graphene oxide ( $\mathrm{rGO}$ ) materials [1, 2]. Although incomplete exfoliation of graphite to the level of individual graphene sheets might occur, this method allows the synthesis of rGO in high yields, since large-scale production of its precursor (GO) is reliable, resulting in low production costs $[1,2]$.

At the same time, different carbon materials (e.g. activated carbons, activated carbon xerogels, carbon nanotubes, graphite and carbon blacks) have been reported as metal-free catalysts for the catalytic wet peroxide oxidation (CWPO) of toxic and bio-recalcitrant organic pollutants in aqueous phase [5-10] - commonly associated with negative impacts on conventional biological wastewater treatment processes. Specifically, CWPO is an advanced oxidation process (AOP) involving the transference of electrons from the active sites of a 
suitable catalyst to hydrogen peroxide $\left(\mathrm{H}_{2} \mathrm{O}_{2}\right)$ molecules, in order to decompose them through reduction of $\mathrm{H}_{2} \mathrm{O}_{2}$ to hydroxyl radicals $\left(\mathrm{HO}^{\circ}\right)$ and hydroxide ions $\left(\mathrm{OH}^{-}\right)$, the former exhibiting high oxidizing potential and serving as effective species for the degradation of several organic pollutants in liquid phase [11-13]. Thus, materials containing electron donating active sites available for $\mathrm{H}_{2} \mathrm{O}_{2}$ decomposition should be more efficient in CWPO [13, 14].

In the present work, aiming to explore the presence of electron donating active sites at the surface of graphene-based materials, and their unique structural and electronic transfer properties, rGO samples were prepared from GO using different reducing agents (i.e., glucose, hydrazine and vitamin C) and subsequently tested in the CWPO process performed under mild conditions.

Furthermore, although most applications for the CWPO process typically deal with pollutants present in water at low concentrations (up to $0.1 \mathrm{~g} \mathrm{~L}^{-1}$ ), recent works show that the efficiency of this treatment option may be increased when operating at high pollutant loads (in the range $\left.0.5-5 \mathrm{~g} \mathrm{~L}^{-1}\right)[6,15,16]$. Therefore, in order to explore this possibility, the CWPO experiments were performed using a high pollutant load of $5 \mathrm{~g} \mathrm{~L}^{-1}$. 4-Nitrophenol (4-NP) was used as non-biodegradable model pollutant.

\section{Materials and methods}

\subsection{Chemicals}

4-Nitrophenol, 4-NP $\left(\mathrm{O}_{2} \mathrm{NC}_{6} \mathrm{H}_{4} \mathrm{OH}, \mathrm{Mr} 139.11,98\right.$ wt.\%) [CAS number: 100-02-7], was purchased from Acros Organics. Hydrogen peroxide $\left(\mathrm{H}_{2} \mathrm{O}_{2}, 30 \%\right.$ w/v) was obtained from Fluka. Sodium hydroxide $(\mathrm{NaOH}, 98$ wt.\%) was obtained from Panreac and potassium permanganate $\left(\mathrm{KMnO}_{4}, 99\right.$ wt.\%) from Merck. Sulphuric acid $\left(\mathrm{H}_{2} \mathrm{SO}_{4}, 96-98\right.$ wt.\%) was obtained from Riedel-de-Haën. Hydrazine hydrate $\left(\mathrm{NH}_{2} \mathrm{NH}_{2} \cdot \mathrm{H}_{2} \mathrm{O}, \quad 50-60\right.$ wt.\%), D-(+)-Glucose $\left(\mathrm{C}_{6} \mathrm{H}_{12} \mathrm{O}_{6}, 99.5\right.$ wt.\%), L-ascorbic acid $\left(\mathrm{C}_{6} \mathrm{H}_{8} \mathrm{O}_{6}, 99\right.$ wt.\%), titanium (IV) 
oxysulphate $\left(\mathrm{TiOSO}_{4} \cdot \mathrm{xH}_{2} \mathrm{O}, 15\right.$ wt.\% in dilute sulphuric acid, 99.99\%), hydrochloric acid ( $\mathrm{HCl}, 37$ wt.\%) and sodium sulphite $\left(\mathrm{Na}_{2} \mathrm{SO}_{3}, 98\right.$ wt.\%) were purchased from Sigma-Aldrich. Methanol (HPLC grade), glacial acetic acid (analytical reagent grade) and acetonitrile (HPLC grade) were obtained from Fisher chemical. All chemicals were used as received without further purification. Distilled water was used throughout the work.

\subsection{Synthesis of graphene oxide}

GO was synthesized from natural graphite (particle size $\leq 20 \mu \mathrm{m}$, from Sigma-Aldrich), by a modified Hummers method [17, 18] described elsewhere [19]. Concentrated sulphuric acid $(50 \mathrm{~mL})$ was added gradually with stirring and cooling to a $500 \mathrm{~mL}$ flask containing $2 \mathrm{~g}$ of graphite. Then, $6 \mathrm{~g}$ of potassium permanganate were added slowly to the mixture. The suspension was continuously stirred for $2 \mathrm{~h}$ at $308 \mathrm{~K}$. After that, it was cooled in an ice bath and subsequently diluted with $350 \mathrm{~mL}$ of distilled water. Afterwards, $\mathrm{H}_{2} \mathrm{O}_{2}(30 \%$ w/v) was added in order to reduce residual permanganate to soluble manganese ions, a bright yellow colour appearing in the suspension. The oxidized material was purified with an hydrochloric acid solution (10 wt.\%) and the suspension was then filtered, washed several times with distilled water until the neutrality of the rinsing waters was reached, and dried at $333 \mathrm{~K}$ for $24 \mathrm{~h}$ to obtain graphite oxide. The resulting material was dispersed in a given volume of water and sonicated in an ultrasound bath (ultrasonic processor UP400S, $24 \mathrm{kHz}$ ) for $1 \mathrm{~h}$. The sonicated dispersion was centrifuged for $20 \mathrm{~min}$ at $3000 \mathrm{rpm}$ to remove unexfoliated graphite oxide particles from the supernatant, GO being obtained in this way (ash content of ca. 0.06 wt. $\%$, as determined by thermogravimetric analysis).

\subsection{Chemical reduction of graphene oxide}

rGO samples were obtained by chemical reduction of GO using vitamin C (rGOV) [20], glucose (rGOG) [21] and hydrazine (rGOH) [22] as reducing agents and employing the aqueous dispersion of $\mathrm{GO}$, as described elsewhere [23]. Namely, the GO suspension 
$\left(0.1 \mathrm{~g} \mathrm{~L}^{-1}\right)$ containing the reducing agent $\left(2 \mathrm{mmol} \mathrm{L}^{-1}\right)$ was heated at $368 \mathrm{~K}$ for $3 \mathrm{~h}$ under vigorous stirring. Before reduction, the $\mathrm{pH}$ of the $\mathrm{GO}$ dispersion was adjusted to 9-10 with a $25 \%$ ammonia solution to promote the colloidal stability of the GO sheets through electrostatic repulsion.

\subsection{Characterization techniques}

The textural properties of the graphene-based materials were determined from $\mathrm{N}_{2}$ adsorption-desorption isotherms at $77 \mathrm{~K}$, obtained in a Quantachrome NOVA 4200e adsorption analyser. Before the analysis, all samples were outgassed for $8 \mathrm{~h}$ at $393 \mathrm{~K}$. The apparent surface area $\left(S_{\mathrm{BET}}\right)$ was determined by applying the Brunauer-Emmett-Teller $(\mathrm{BET})$ equation [24]. The micropore volume $\left(V_{\text {micro }}\right)$ and the non-microporous surface area $\left(\mathrm{S}_{\text {meso }}\right)$ was determined by the $t$-method using an appropriate standard isotherm [25].

Thermogravimetric analysis was performed using a STA 490 PC/4/H Luxx Netzsch thermal analyser, by heating the sample in an air flow from $323 \mathrm{~K}$ to $1273 \mathrm{~K}$ at $20 \mathrm{~K} \mathrm{~min}^{-1}$.

The point of zero charge $\left(\mathrm{pH}_{\mathrm{PZC}}\right)$ of the graphene-based materials was determined following the methodology described elsewhere [26]. Briefly, solutions with varying initial $\mathrm{pH}(2-12)$ were prepared using $\mathrm{HCl}\left(0.1 \mathrm{~mol} \mathrm{~L}^{-1}\right)$ or $\mathrm{NaOH}\left(0.1 \mathrm{~mol} \mathrm{~L}^{-1}\right)$ and $50 \mathrm{~mL}$ of $\mathrm{NaCl}$ $\left(0.01 \mathrm{~mol} \mathrm{~L}^{-1}\right)$ as electrolyte. Each solution was contacted with $0.15 \mathrm{~g}$ of the carbon material and the final $\mathrm{pH}$ was measured after $24 \mathrm{~h}$ of continuous stirring at room temperature. The $\mathrm{pH}_{\mathrm{PZC}}$ value of the material was determined by intercepting the obtained final $\mathrm{pH}$ vs. initial $\mathrm{pH}$ curve with the straight line final $\mathrm{pH}=$ initial $\mathrm{pH}[27,28]$.

Temperature Programmed Desorption (TPD) was performed in a fully automated AMI-300 Catalyst Characterization Instrument (Altamira Instruments), equipped with a quadrupole mass spectrometer (Dymaxion, Ametek). The carbon sample $(0.10 \mathrm{~g})$ was placed in a U-shaped quartz tube inside an electrical furnace and heated at $5 \mathrm{~K} \mathrm{~min}^{-1}$ up to $1073 \mathrm{~K}$ using a constant flow rate of helium $\left(25 \mathrm{~cm}^{3} \mathrm{~min}^{-1}\right)$. The mass signals $\mathrm{m} / \mathrm{z}=28$ and 44 were 
monitored during the thermal analysis, the corresponding TPD spectra being obtained. CO and $\mathrm{CO}_{2}$ were calibrated at the end of each analysis with the respective gases [29].

\subsection{Catalytic wet peroxide oxidation experiments}

Batch CWPO experiments were performed in a $250 \mathrm{~mL}$ well-stirred $(600 \mathrm{rpm})$ glass reactor equipped with a condenser, a temperature measurement thermocouple, a $\mathrm{pH}$ measurement electrode and a sample collection port. The reactor was loaded with $50 \mathrm{~mL}$ of a 4-NP aqueous solution $\left(5.0 \mathrm{~g} \mathrm{~L}^{-1}\right)$ and heated by immersion in an oil bath at controlled temperature. Upon stabilization at the desired temperature, the solution $\mathrm{pH}$ was adjusted to 3 by means of $\mathrm{H}_{2} \mathrm{SO}_{4}$ and $\mathrm{NaOH}$ solutions, and the experiments were allowed to proceed freely, without further adjustment of the $\mathrm{pH}$. A calculated volume of $\mathrm{H}_{2} \mathrm{O}_{2}(30 \% \mathrm{w} / \mathrm{v})$ was injected into the system, in order to reach the stoichiometric amount of $\mathrm{H}_{2} \mathrm{O}_{2}$ needed to completely mineralise 4-NP $\left(17.8 \mathrm{~g} \mathrm{~L}^{-1}\right)$. The catalyst was added after complete homogenization of the resulting solution, that moment being considered as $t_{0}=0 \mathrm{~min}$. Pure adsorption runs were also performed in order to discriminate between adsorption and catalytic components of 4-NP removal by CWPO, but, in this case, the amount of $\mathrm{H}_{2} \mathrm{O}_{2}$ was replaced by distilled water. The experiments were conducted during $24 \mathrm{~h}$, at $T=323 \mathrm{~K}, \mathrm{pH}=3$ and catalyst/adsorbent load $=2.5 \mathrm{~g} \mathrm{~L}^{-1}$ (corresponding to a 4-NP/catalyst mass ratio $=2$ ). Blank experiments, without any catalyst, were also carried out to assess possible non-catalytic oxidation promoted by $\mathrm{H}_{2} \mathrm{O}_{2}$.

\subsection{Analytical methods}

The concentration of 4-NP was determined by high performance liquid chromatography (HPLC), adapting the procedure described elsewhere [30]. For that purpose, small aliquots were periodically withdrawn from the reactor and an excess of sodium sulphite was immediately added in order to consume residual $\mathrm{H}_{2} \mathrm{O}_{2}$ and to instantaneously stop the reaction [10, 31, 32]. A Jasco HPLC system equipped with an UV/Vis detector (UV-2075 Plus), a 
quaternary gradient pump (PU-2089 Plus) for solvent delivery $\left(1 \mathrm{~mL} \mathrm{~min}^{-1}\right)$ and a Kromasil 100-5-C18 column (15 cm x $4.6 \mathrm{~mm} ; 5 \mu \mathrm{m}$ particle size) was employed. Mobile phase consisted in an isocratic method of A:B (40:60) mixture of $3 \%$ acetic acid and $1 \%$ acetonitrile in methanol (A) and 3\% acetic acid in ultrapure water (B). The 4-NP absorbance peaked at $318 \mathrm{~nm}$, as determined from the corresponding UV-Vis absorption spectrum (Jasco V530). Possible intermediates of 4-NP oxidation (e.g., hydroquinone, 1,4-benzoquinone, 4-nitrocatechol, catechol and phenol) were monitored using the same system, the absorbance wavelength being adjusted to $277 \mathrm{~nm}$.

The formation and evolution of nitrates and carboxylic acids (e.g., formic, acetic, oxalic, malonic, maleic and malic acids) were also monitored using the same Jasco HPLC system, this time equipped with an YMC - Triart C18 column ( $25 \mathrm{~cm}$ x $4.6 \mathrm{~mm} ; 5 \mu \mathrm{m}$ particle size), adapting procedures reported elsewhere [33, 34]. Mobile phase consisted in an isocratic method of A:B (95:5) mixture of $1 \%$ sulphuric acid in ultrapure water (A) and acetonitrile (B), delivered to the system at $0.6 \mathrm{~mL} \mathrm{~min}^{-1}$. The UV/Vis detector was set to $210 \mathrm{~nm}$.

The concentration of $\mathrm{H}_{2} \mathrm{O}_{2}$ was followed by a colorimetric method [35], adapted from procedures described elsewhere [36]. For that purpose, a filtered sample was added to $1 \mathrm{~mL}$ of sulphuric acid solution $\left(0.5 \mathrm{~mol} \mathrm{~L}^{-1}\right)$ in a $20 \mathrm{~mL}$ volumetric flask, to which $0.1 \mathrm{~mL}$ of titanium oxysulfate were added. The resulting mixture was diluted with distilled water and further analysed by UV-Vis spectrophotometry (T70 spectrometer, PG Instruments, Ltd.).

Total organic carbon (TOC) was determined using a Rosemount Analytical Dohrmann DC-190 analyser. 


\section{Results and discussion}

\subsection{Texture and surface chemical characterization}

All the graphene-based materials used in this work were extensively characterized in our previous publication related to the synthesis of graphene-based $\mathrm{TiO}_{2}$ composites for photocatalysis [23]. Notwithstanding, some textural and surface chemical properties were further explored throughout this work. Thus, for the sake of discussion, the most relevant data are presented in this Section.

Figure 1 shows the $\mathrm{N}_{2}$ adsorption-desorption isotherms at $77 \mathrm{~K}$ of the graphene-based materials. All isotherms can be described as type-II, in accordance with IUPAC classification [36]. It is noteworthy that both rGOG and rGOH present some microporosity, corresponding to the amount of $\mathrm{N}_{2}$ adsorbed at low relative pressure $\left(V_{\text {micro }}\right.$ of $0.004 \mathrm{~cm}^{3} \mathrm{~g}^{-1}$ and $0.039 \mathrm{~cm}^{3} \mathrm{~g}^{-1}$ for rGOG and $\mathrm{rGOH}$, respectively, cf. Table 1), but the progressive increase of the amount of $\mathrm{N}_{2}$ adsorbed at higher relative pressures, as well as the formation of a hysteresis loop of type $\mathrm{H} 3$ in both samples, denotes a strong influence of mesoporosity, typical of adsorbents with slit-shaped pores. On the other hand, both GO and rGOV present isotherms of non-porous materials with small surface area. This may be due to overlapping and stacking of the exfoliated layers. The hysteresis loop could be related with "swelling" or "breathing" effects in the flexible framework induced by the sorbate.

\section{FIGURE 1}

From the apparent surface areas $\left(S_{\mathrm{BET}}\right)$ of the GO and rGO samples (shown in Table 1), it is observed that $\mathrm{S}_{\mathrm{BET}}$ is affected differently by the type of reducing agent that is employed. This effect can be attributed to the distinct extents of structural defects occurring with different reducing agents, as observed through Raman spectroscopy in Table 2, where are collected the Raman intensity ratios of the $\mathrm{D}$ bands relative to the $\mathrm{G}$ mode $\left(I_{\mathrm{D}} / I_{\mathrm{G}}\right)$ obtained for the rGO samples, calculated from the areas of the corresponding Raman bands, at $514.5 \mathrm{~nm}$ 
and $785 \mathrm{~nm}$, respectively. As can be observed, rGOG presents the lowest $I_{\mathrm{D}} / I_{\mathrm{G}}$ values, suggesting that it contains the lowest amount of defects [23], followed by rGOV and rGOH.

\section{TABLE 1}

As previously reported [23], and here shown in Table 1, an increase of $\mathrm{pH}_{\mathrm{PZC}}$ values was observed for the rGO samples (ranging from 5.1 to 5.5) compared to GO (2.8), showing that the carbon surface becomes less acidic after the chemical treatments with different agents (also confirmed by the TPD results collected in Table 3), due to the removal of acidic surface functional groups from GO.

\section{TABLE 2}

The total amounts of $\mathrm{CO}$ and $\mathrm{CO}_{2}$ released by TPD, as well as the oxygen contents for the graphene-based materials, before and after CWPO experiments, are presented in Table 3. In order to obtain more detailed information about the different types of oxygen containing groups in the rGO samples, deconvolution of the TPD spectra was also carried out for the samples before and after CWPO. The results are summarized in Tables 4 and 5 and in Figure 2a-b, c-d and e-f, for rGOG, rGOH and rGOV, respectively. The deconvolution methodology was applied considering the temperatures at which the different groups are evolved as $\mathrm{CO}$ and $\mathrm{CO}_{2}$ upon heating and some assumptions made in accordance to the methodology reported elsewhere $[29,38]$.

\section{TABLE 3}

Analysis of the fresh samples (i.e., before being used in CWPO), reveals that the oxygen amount evolved during the TPD analysis is significantly larger in the case of GO (24 wt.\%) when compared to the rGO samples (about $6 \mathrm{wt} . \%$ ), as summarized in Table 3. A similar trend was found for the efficiency of the GO chemical treatment, regardless of the selected reducing agent, as previously reported [23]. The most labile oxygen functional groups were identified as epoxy and hydroxyl groups, located on basal planes of GO. These groups are 
removed during the reduction process, whereas the more stable groups located on the edges (e.g., carbonyl and carboxylic groups) are only partially reduced [23].

\section{TABLE 4}

\section{TABLE 5}

When the fresh rGO samples are compared to those recovered from the CWPO runs, a significant increase of the oxygen content is observed, indicating that the CWPO process affects the surface chemistry of the rGO samples. This effect is more pronounced in the case of rGOG, an increase from $5.8 \mathrm{wt} . \%$ to $32.1 \mathrm{wt} . \%$ being observed.

Furthermore, the deconvolution of the $\mathrm{CO}_{2}$ spectra of the rGO samples before and after CWPO runs (Figure 2a, $\mathrm{c}$ and e, for $\mathrm{rGOG}, \mathrm{rGOH}$ and $\mathrm{rGOV}$, respectively), indicates that carboxylic acid groups, namely strongly acidic carboxylic groups/ 500-550 K (SA) and weakly acidic carboxylic groups/ 600-640 K (WA), as well as anhydride groups/660-760 K $(C A n)$ and lactone groups/ 880-980 K $(\mathrm{Lac})$, are all incorporated in the samples during the CWPO runs. Regarding the CO spectra, carboxylic acids/ 510-570 K (SA), carboxylic anhydrides/ 710-790 K $\quad(C A n), \quad$ phenols/ 900-950 K $\quad(P h)$ and carbonyl/quinone groups/1060-1300 $\mathrm{K}(C Q)$ are also incorporated during the CWPO runs, as shown in Figure $2 \mathrm{~b}, \mathrm{~d}$ and $\mathrm{f}$ for rGOG, rGOH and rGOV, respectively. For the rGO samples after the CWPO experiments, it is noteworthy the presence of the peak at low temperature $(\sim 471 \mathrm{~K})$ in both $\mathrm{CO}_{2}$ and $\mathrm{CO}$ spectra, assigned to the basal plane epoxy and hydroxyl groups $(E \& H)$. This peak was not observed in the rGO samples before the CWPO runs since the epoxy and hydroxyl groups located on the basal planes of GO were removed during the chemical reduction treatments [23].

\section{FIGURE 2}




\section{2. $C W P O$ experiments}

The catalytic activity of the graphene-based materials in the CWPO of highly concentrated 4-NP solutions was evaluated in screening experiments performed under the conditions referred in Section 2.5. The corresponding 4-NP removal curves are collected in Figure 3. These preliminary results suggest that the performances of the rGO samples are largely superior to the performance of their precursor (GO). However, in addition to the catalytic reaction, CWPO also has an adsorption contribution. Therefore, in order to understand the influence of adsorption in the global performance of the catalysts, pure adsorption experiments were also carried out with all the graphene-based materials.

\section{FIGURE 3}

The removals of 4-NP obtained by pure adsorption and by CWPO in the presence of the graphene-based materials, in $24 \mathrm{~h}$ runs, are given in Figure 4. These results show that all the graphene-based materials are, unequivocally, active catalysts for the CWPO of highly concentrated 4-NP solutions at mild conditions, since the removals of 4-NP obtained in CWPO runs are markedly superior to the removals obtained by pure adsorption. In order to better assess the catalytic performance of the graphene-based materials, the parameter $d_{\text {Removal }}$ was introduced - corresponding to the difference in the 4-NP percent removal between CWPO and pure adsorption experiments. Bearing this definition in mind, and taking into account the values of $d_{\text {Removal }}$ shown in Figure 4, it can be concluded that the catalytic activity of the graphene-based materials follows the sequence: $\mathrm{rGOV}>\mathrm{rGOH}>\mathrm{rGOG}>\mathrm{GO}$. Specifically, the use of rGOV as catalyst allows a 4-NP removal of $1294 \mathrm{mg} \mathrm{g}^{-1}$. The highest removal of 4-NP is observed when using rGOG (1298 $\left.\mathrm{mg} \mathrm{g}^{-1}\right)$ but, in this case, pure adsorption experiments indicate that a larger adsorption of 4-NP may occur on the surface of this carbon material during CWPO. 
In the absence of a catalyst, the 4-NP removal obtained after $24 \mathrm{~h}$ of reaction does not reach $7 \%$ of its initial content ( $c f$. Figure 3 and Figure 4). Therefore, the non-catalytic removal of 4-NP may be considered negligible.

Given that the best performances in the CWPO of 4-NP were observed when the rGO samples were used as catalysts, only these graphene-based materials were selected for further studies.

\section{FIGURE 4}

\subsubsection{Efficiency of $\mathrm{H}_{2} \mathrm{O}_{2}$ consumption}

TOC and $\mathrm{H}_{2} \mathrm{O}_{2}$ evolution were also monitored during the CWPO runs performed with the rGO samples. This methodology enables a more detailed analysis regarding their catalytic activity, based on the TOC and $\mathrm{H}_{2} \mathrm{O}_{2}$ removals $\left(X_{\mathrm{TOC}}\right.$ and $X_{\mathrm{H}_{2} \mathrm{O}_{2}}$, respectively) obtained at the end of each CWPO run $(24 \mathrm{~h})$. Although the TOC removal was found to be quite similar $\left(23.0 \% \leq X_{\mathrm{TOC}} \leq 24.7 \%\right), X_{\mathrm{H}_{2} \mathrm{O}_{2}}$ ranges from $30.4 \%(\mathrm{rGOG})$ to $54.7 \%$ (rGOH). These observations suggest that the products resulting from the decomposition of $\mathrm{H}_{2} \mathrm{O}_{2}$ catalysed by the rGO samples might proceed via distinct catalytic reaction pathways; for instance, it is known that $\mathrm{H}_{2} \mathrm{O}_{2}$ can be catalytically decomposed via formation of $\mathrm{HO}^{\circ}$ radicals with further efficient reaction of $\mathrm{HO}^{\circ}$ radicals with the organic pollutants; or end up with the formation of oxygen and water, resulting from non-efficient parasite reactions occurring between formed $\mathrm{HO}^{\circ}$ radicals and $\mathrm{H}_{2} \mathrm{O}_{2}$ molecules. The different reaction pathways depend on the combination of several surface and structural properties of the catalysts $[13,14]$.

In order to enquire about the quality of the $\mathrm{H}_{2} \mathrm{O}_{2}$ decomposition at the surface of the rGO samples, the parameter $\eta_{\mathrm{H}_{2} \mathrm{O}_{2}}$ was introduced - corresponding to the TOC removal per unit of $\mathrm{H}_{2} \mathrm{O}_{2}$ decomposed, obtained when $X_{\text {TOC }}$ is divided by $X_{\mathrm{H}_{2} \mathrm{O}_{2}}$. Values in the range of $45.2 \%$ to $75.6 \%$ were obtained through this approach, the $\eta_{\mathrm{H}_{2} \mathrm{O}_{2}}$ following the sequence: $\mathrm{rGOG}>\mathrm{rGOV}$ $>\mathrm{rGOH}$. When these results are analysed together with the results given in Table 3 , it can be 
observed that $\eta_{\mathrm{H}_{2} \mathrm{O}_{2}}$ decreases with the increase of the surface oxygen content of the rGO samples. The main active sites at the surface of the graphene-based materials are at electron rich regions, generated from the delocalized $\pi$-electron network. These will be the sites used to convert $\mathrm{H}_{2} \mathrm{O}_{2}$ to hydroxyl radicals $\left(\mathrm{HO}^{\circ}\right)$, or to reduce it to hydroxide ions $\left(\mathrm{OH}^{-}\right)$. Thus, the presence of electron withdrawing species, such as the surface oxygen-containing functionalities of carbon catalysts, are expected to reduce the number of electron rich regions for the catalytic reaction, and thus to limit the catalytic performance of the materials $[13,14$, $39,40]$.

Furthermore, clear relationships are also found when $\eta_{\mathrm{H}_{2} \mathrm{O}_{2}}$ is analysed together with the apparent structural disorder (Table 2) and the 4-NP adsorption behaviour (Figure 4) of the rGO samples. First, it is observed that, in the particular case of the rGO samples employed in our study, higher amounts of structural defects lead to lower values of $\eta_{\mathrm{H}_{2} \mathrm{O}_{2}}$, although graphene-based materials with higher amounts of structural defects resulted in increased catalytic decomposition of $\mathrm{H}_{2} \mathrm{O}_{2}$. The relationship becomes evident when $\eta_{\mathrm{H}_{2} \mathrm{O}_{2}}$ is plotted against the intensity ratios of the $\mathrm{D}$ bands relative to the $\mathrm{G}$ mode $\left(I_{\mathrm{D}} / I_{\mathrm{G}}\right)$ for the rGO samples (Figure 5). This may be explained by confinement of the electron rich regions caused by the structural defects, leading to an increase of electron density at those regions which act as active sites for the reaction, increasing the generation of $\mathrm{HO}^{\bullet}$ radicals. However, higher concentration of $\mathrm{HO}^{\bullet}$ radicals will not necessarily lead to higher efficiency of the CWPO process, since the amount of parasitic reactions is also expected to increase significantly, thus reducing $\eta_{\mathrm{H}_{2} \mathrm{O}_{2}}$. Second, it is also observed that $\eta_{\mathrm{H}_{2} \mathrm{O}_{2}}$ follows the same order as the extent of 4-NP adsorption (Figure 4) on the surface of the rGO samples. Thus, in the particular case of the rGO samples, the balance between a more controlled catalytic decomposition of $\mathrm{H}_{2} \mathrm{O}_{2}$, together with higher pollutant concentration nearby the generated $\mathrm{HO}^{\circ}$ radicals, leads to the highest efficiency of the CWPO process. These observations suggest that $\eta_{\mathrm{H}_{2} \mathrm{O}_{2}}$ is favoured by 
higher pollutant concentrations at the surface of the catalysts, explained by a more efficient use of the $\mathrm{HO}^{\bullet}$ radicals formed nearby the adsorbed molecules leading to further oxidation. These results are in line with another work reporting the lower extent of non-efficient parasite reactions occurring between $\mathrm{HO}^{\circ}$ radicals and $\mathrm{H}_{2} \mathrm{O}_{2}$ molecules, resulting in the formation of oxygen and water, when the CWPO process was performed with similar pollutant/catalyst ratios [15].

\section{FIGURE 5}

\subsubsection{Reusability cycles}

Although in different extents, all the rGO samples (rGOV, rGOH and rGOG) exhibited catalytic activity for the CWPO of highly concentrated 4-NP solutions. Thus, all these materials were selected for further studies on their catalytic stability in the CWPO process an essential requirement for industrial scale applications. For that purpose, reusability cycles were performed in the following way: after each run, the catalyst was filtered, washed and dried at $333 \mathrm{~K}$ overnight, and then reused in CWPO, considering a fresh 4-NP solution. The 4-NP, TOC and $\mathrm{H}_{2} \mathrm{O}_{2}$ removals, as well as the corresponding $\eta_{\mathrm{H}_{2} \mathrm{O}_{2}}$ obtained after $24 \mathrm{~h}$ of reaction in this series of three experiments are given in Figure 6.

Different behaviours are observed in respect to the rGO samples stability. In the case of rGOG, the removal of 4-NP decreases from $1298 \mathrm{mg} \mathrm{g}^{-1}$, in the first run, to $700 \mathrm{mg} \mathrm{g}^{-1}$ and $426 \mathrm{mg} \mathrm{g}^{-1}$, in the second and third runs, respectively. Likewise, the TOC removal also decreases. In the opposite trend, the $\eta_{\mathrm{H}_{2} \mathrm{O}_{2}}$ obtained after $24 \mathrm{~h}$ of reaction in this series of three experiments performed with rGOG increases during its successive reuse, reaching a value as high as $98.1 \%$ in the third run. When $\mathrm{rGOH}$ is considered, it can be seen that the catalytic activity of this graphene-based material is kept without noteworthy variation during its successive reuse. Specifically, the removal of 4-NP decreases from around $980 \mathrm{mg} \mathrm{g}^{-1}$, in the first and second runs, to $841 \mathrm{mg} \mathrm{g}^{-1}$, in the third run. Furthermore, the TOC removal reaches 
$256 \mathrm{mg} \mathrm{g}^{-1}$, in the first run, decreasing to a still significant $139 \mathrm{mg} \mathrm{g}^{-1}$. Finally, both 4-NP and TOC removals gradually decrease during the successive reuse of rGOV. Therefore, from a general point of view, the data given in Figure 6 allow to conclude that rGOH presents the highest catalytic stability among the tested graphene-based materials.

In order to allow a better understanding of the catalytic stability of each rGO material, TPD analysis of the samples recovered after the first CWPO run was performed ( $c f$. Table 3, Table 4, Table 5 and Figure 2). Analysing all these results together with the results given in Figure 6 , it can be concluded that the oxygen content at the surface of the materials plays a major role in the catalytic stability of the rGO samples. For instance, rGOG - the sample with the highest increase of oxygen functionalities during the CWPO process - also shows the most pronounced decrease of catalytic activity. On the other hand, $\mathrm{rGOH}$ - the sample with the lowest increase of oxygen functionalities during the CWPO process - was found as the most stable material for the CWPO of highly concentrated 4-NP solutions.

\section{FIGURE 6}

\subsubsection{Oxidation mechanism}

In order to understand the oxidation/mineralization mechanism in the CWPO of highly concentrated 4-NP solutions, performed at mild conditions and using graphene-based materials as catalysts, the presence of some possible intermediates and by-products was explored. Since the highest catalytic activity was found for the rGOV sample ( $c f$. Figure 4), the time-evolution of aromatic and non-aromatic compounds resulting from the CWPO of 4-NP performed with this material was followed, as given in Figure 7a and b, respectively. Based on the identified compounds, the mechanism depicted in Figure 8 was proposed.

\section{FIGURE 7}

It is well known that the reaction mechanism of $\mathrm{HO}^{\circ}$ radicals with aromatic compounds proceeds mainly through an electrophilic addition to the aromatic ring [41-43]. 
The phenolic $-\mathrm{OH}$ group is electron-donating for the electrophilic aromatic substitution, thus increasing the electron density both in the ortho and in the para positions [41]. On the other hand, the $-\mathrm{NO}_{2}$ group is electron-withdrawing, thus being meta directing [41]. In the particular case of 4-NP (i.e., in the presence of both substituents), the electrophilic attack will occur at the ortho position in respect to the $-\mathrm{OH}$ group, leading to the formation of 4-nitrocatechol [41, 43]. As it can be observed, this mechanism is well evidenced in Figure 7a, since 4-nitrocatechol is the main aromatic intermediate of the 4-NP mineralization by CWPO.

Furthermore, an aromatic substitution of the $-\mathrm{NO}_{2}$ group may occur due to an ipso attack of the radical $\mathrm{HO}^{\circ}$ at the para position in respect to the $-\mathrm{OH}$ group, hydroquinone being obtained [42, 43]. Hydroquinone was also identified as an intermediate of the 4-NP mineralization through CWPO (Figure 7a), although in a smaller extent when compared to 4-nitrocatechol. On the other hand, hydroquinone is known to be very easily oxidized into benzoquinone [43]. Thus, benzoquinone formation would be expected from the reaction of hydroquinone with highly oxidizing species such as $\mathrm{HO}^{\circ}$ radicals. As can be seen in Figure 7a, benzoquinone was effectively detected in the final stage of the experiment. Trace amounts of catechol were also detected, probably resulting from the $-\mathrm{NO}_{2}$ group cleavage and subsequent electrophilic attack of the $\mathrm{HO}^{\circ}$ radical at the ortho position.

Further attacks of $\mathrm{HO}^{\circ}$ radicals on these aromatic intermediate compounds will eventually lead to the aromatic ring opening, and thus to the formation of a series of low molecular weight carboxylic acids, which subsequently are mineralized to carbon dioxide and water $[42,43]$. In this study, several carboxylic acids were investigated (e.g., formic, acetic, oxalic, malonic, maleic and malic acids). Nevertheless, only four were effectively detected and quantified ( $c f$. Figure $7 \mathrm{~b}$ ). Malonic acid was the main carboxylic acid detected.

Finally, nitrates can be produced from the $-\mathrm{NO}_{2}$ group of the aromatic ring under the oxidation conditions employed [43]. From the concentration profile of nitrates given in Figure 
$7 \mathrm{~b}$, the effectiveness of the $-\mathrm{NO}_{2}$ group subtraction from the main aromatic rings through the CWPO process is confirmed.

\section{FIGURE 8}

\section{Conclusions}

The main conclusion withdrawn from this work is that graphene-based materials are unequivocally active for the CWPO of highly concentrated 4-NP solutions $\left(5 \mathrm{~g} \mathrm{~L}^{-1}\right)$ at mild conditions (i.e., atmospheric pressure, $T=323 \mathrm{~K}, \mathrm{pH}=3$, [catalyst] $=2.5 \mathrm{~g} \mathrm{~L}^{-1}$ and $\left.\left[\mathrm{H}_{2} \mathrm{O}_{2}\right]_{0}=17.8 \mathrm{~g} \mathrm{~L}^{-1}\right)$.

Regardless of the material employed in the process, the 4-NP removal through CWPO is always higher than the removal obtained by pure adsorption. Nevertheless, rGO samples lead to largely superior performances when compared to the performance of their precursor (GO).

The most active material is rGOV, attaining a 4-NP removal of $1294 \mathrm{mg} \mathrm{g}^{-1}$ and a TOC removal of $241 \mathrm{mg} \mathrm{g}^{-1}$ during $24 \mathrm{~h}$ experiments (corresponding to 4-NP and TOC removals of $65 \%$ and $23 \%$, respectively).

Although the TOC removal reached under these conditions is quite similar for all the catalysts $\left(23.0 \% \leq X_{\mathrm{TOC}} \leq 24.7 \%\right)$, the TOC removal per unit of $\mathrm{H}_{2} \mathrm{O}_{2}$ decomposed varies in a wider range $\left(45.2 \% \leq \eta_{\mathrm{H}_{2} \mathrm{O}_{2}} \leq 75.6 \%\right)$. This suggests that the products resulting from the decomposition of $\mathrm{H}_{2} \mathrm{O}_{2}$ catalysed by the rGO samples might proceed via distinct catalytic reaction pathways. In the particular case of the rGO samples employed in our study, the values of $\eta_{\mathrm{H}_{2} \mathrm{O}_{2}}$ decrease with the increase of the surface oxygen content of the samples, as well as with the increase of the amount of structural defects.

The most stable material is $\mathrm{rGOH}$, displaying in a series of three consecutive runs a slight decrease of the 4-NP removal from $980 \mathrm{mg} \mathrm{g}^{-1}$, in the first and second runs, to $841 \mathrm{mg} \mathrm{g}^{-1}$, in the third run (corresponding to $4-\mathrm{NP}$ removals of $49 \%$ and $42 \%$, respectively). The increase 
of surface oxygen functionalities of the rGO samples during the CWPO runs was considered the main cause for the partial deactivation of the catalysts.

The 4-NP oxidation proceeds by initial aromatic hydroxyl oxidative attack (similar to phenol oxidation) followed by oxidative fragmentation, with release of nitrates, as confirmed by the identification of 4-nitrocatechol, hydroquinone, benzoquinone and catechol. Furthermore, several low molecular weight carboxylic acids were observed, including malonic, malic, maleic and acetic acids, allowing the mechanistic interpretation.

\section{Acknowledgments}

Work supported by project PTDC/AAC-AMB/110088/2009 and partially by projects PEst-C/EQB/LA0020/2013， NORTE-07-0162-FEDER-000050 and NORTE-07-0124FEDER-0000015, co-financed by FEDER through COMPETE, QREN and ON2, and by FCT - Fundação para a Ciência e a Tecnologia. RSR and LMPM acknowledge financial support from the FCT grants SFRH/BD/94177/2013 and SFRH/BPD/88964/2012, respectively. A.M.T. Silva acknowledges the FCT Investigator 2013 Programme (IF/01501/2013), with financing from the European Social Fund and the Human Potential Operational Programme. 


\section{References}

[1] B.F. Machado, P. Serp, Catal. Sci. Technol. 2 (2011) 54-75.

[2] S. Morales-Torres, L.M. Pastrana-Martínez, J.L. Figueiredo, J.L. Faria, A.M.T. Silva, Environ. Sci. Pollut. Res. Int. 19 (2012) 3676-3687.

[3] C.N.R. Rao, A.K. Sood, K.S. Subrahmanyam, A. Govindaraj, Angew. Chem. Int. Ed. 48 (2009) 7752-7777.

[4] A.K. Geim, K.S. Novoselov, Nat. Mater. 6 (2007) 183-191.

[5] A. Dhaouadi, N. Adhoum, Appl. Catal., B 97 (2010) 227-235.

[6] C.M. Domínguez, P. Ocón, A. Quintanilla, J.A. Casas, J.J. Rodríguez, Appl. Catal., B 144 (2014) 599-606.

[7] H.T. Gomes, S.M. Miranda, M.J. Sampaio, A.M.T. Silva, J.L. Faria, Catal. Today 151 (2010) 153-158.

[8] F. Lücking, H. Köser, M. Jank, A. Ritter, Water Res. 32 (1998) 2607-2614.

[9] R.S. Ribeiro, N.A. Fathy, A.A. Attia, A.M.T. Silva, J.L. Faria, H.T. Gomes, Chem. Eng. J. 195-196 (2012) 112-121.

[10] R.S. Ribeiro, A.M.T. Silva, J.L. Figueiredo, J.L. Faria, H.T. Gomes, Appl. Catal., B 140 (2013) 356-362.

[11] P.R. Gogate, A.B. Pandit, Adv. Environ. Res. 8 (2004) 501-551.

[12] M. Kimura, I. Miyamoto, Bull. Chem. Soc. Jpn. 67 (1994) 2357-2360.

[13] R.S. Ribeiro, A.M.T. Silva, J.L. Figueiredo, J.L. Faria, H.T. Gomes, Carbon 62 (2013) 97-108.

[14] A. Rey, J.A. Zazo, J.A. Casas, A. Bahamonde, J.J. Rodríguez, Appl. Catal., A 402 (2011) 146-155

[15] C.M. Domínguez, P. Ocón, A. Quintanilla, J.A. Casas, J.J. Rodríguez, Appl. Catal., B 140-141 (2013) 663-670. 
[16] R.S. Ribeiro, A.M.T. Silva, M.T. Pinho, J.L. Figueiredo, J.L. Faria, H.T. Gomes, Catal. Today (2014), http://dx.doi.org/10.1016/j.cattod.2014.03.048.

[17] W.S. Hummers, R.E. Offeman, J. Am. Chem. Soc. 80 (1958) 1339-1339.

[18] S. Stankovich, D.A. Dikin, R.D. Piner, K.A. Kohlhaas, A. Kleinhammes, Y. Jia, Y. Wu, S.T. Nguyen, R.S. Ruoff, Carbon 45 (2007) 1558-1565.

[19] L.M. Pastrana-Martínez, S. Morales-Torres, V. Likodimos, J.L. Figueiredo, J.L. Faria, P. Falaras, A.M.T. Silva, Appl. Catal., B 123-124 (2012) 241-256.

[20] M.J. Fernández-Merino, L. Guardia, J.I. Paredes, S. Villar-Rodil, P. Solís-Fernández, A. Martínez-Alonso, J.M.D. Tascón, J. Phys. Chem. C 114 (2010) 6426-6432.

[21] C. Zhu, S. Guo, Y. Fang, S. Dong, ACS Nano 4 (2010) 2429-2437.

[22] S. Park, J. An, J.R. Potts, A. Velamakanni, S. Murali, R.S. Ruoff, Carbon 49 (2011) 3019-3023.

[23] L.M. Pastrana-Martínez, S. Morales-Torres, V. Likodimos, P. Falaras, J.L. Figueiredo, J.L. Faria, A.M.T. Silva, Appl. Catal., B 158-159 (2014) 329-340.

[24] S. Brunauer, P.H. Emmett, E. Teller, J. Am. Chem. Soc. 60 (1938) 309-319.

[25] F. Rodríguez-Reinoso, A. Linares-Solano, Chemistry and Physics of Carbon 21, 1-146, Marcel Dekker Inc., New York, 1989.

[26] L.M. Pastrana-Martínez, S. Morales-Torres, S.K. Papageorgiou, F.K. Katsaros, G.E. Romanos, J.L. Figueiredo, J.L. Faria, P. Falaras, A.M.T. Silva, Appl. Catal., B 142-143 (2013) 101-111.

[27] M.A. Ferro-García, J. Rivera-Utrilla, I. Bautista-Toledo, C. Moreno-Castilla, Langmuir 14 (1998) 1880-1886.

[28] J. Rivera-Utrilla, I. Bautista-Toledo, M.A. Ferro-García, C. Moreno-Castilla, J. Chem. Technol. Biotechnol. 76 (2001) 1209-1215.

[29] J.L. Figueiredo, M.F.R. Pereira, M.M.A. Freitas, J.J.M. Órfão, Carbon 37 (1999) 13791389. 
[30] Â.C. Apolinário, A.M.T. Silva, B.F. Machado, H.T. Gomes, P.P. Araújo, J.L. Figueiredo, J.L. Faria, Appl. Catal., B 84 (2008) 75-86.

[31] F. Duarte, F.J. Maldonado-Hódar, L.M. Madeira, Appl. Catal., B 103 (2011) 109-115.

[32] J.H. Ramirez, C.A. Costa, L.M. Madeira, G. Mata, M.A. Vicente, M.L. Rojas-Cervantes, A.J. López-Peinado, R.M. Martín-Aranda, Appl. Catal., B 71 (2007) 44-56.

[33] R.P. Rocha, J.P.S. Sousa, A.M.T. Silva, M.F.R. Pereira, J.L. Figueiredo, Appl. Catal., B 104 (2011) 330-336.

[34] L. Yang, L. Liu, B.A. Olsen, M.A. Nussbaum, J. Pharm. Biomed. Anal. 22 (2000) 487493.

[35] W.C. Ketchie, Y.-L. Fang, M.S. Wong, M. Murayama, R.J. Davis, J. Catal. 250 (2007) 94-101.

[36] C.N. Satterfield, A.H. Bonnell, Anal. Chem. 27 (1955) 1174-1175.

[37] K.S.W. Sing, D.H. Everett, R.A.W. Haul, L. Moscou, R.A. Pierotti, J. Rouquérol, T. Siemieniewska, Pure Appl. Chem. 57 (1985) 603-619.

[38] J.L. Figueiredo, M.F.R. Pereira, M.M.A. Freitas, J.J.M. Órfão, Ind. Eng. Chem. Res. 46 (2007) 4110-4115.

[39] V.P. Santos, M.F.R. Pereira, P.C.C. Faria, J.J.M. Órfão, J. Hazard. Mater. 162 (2009) 736-742.

[40] P. Serp, J.L. Figueiredo, Carbon materials for catalysis, John Wiley \& Sons, Inc., Hoboken, New Jersey, 2009.

[41] A. Di Paola, V. Augugliaro, L. Palmisano, G. Pantaleo, E. Savinov, J. Photochem. Photobiol., A 155 (2003) 207-214.

[42] Y. Liu, H.L. Liu, Y. Li, Appl. Catal., B 84 (2008) 297-302.

[43] M.A. Oturan, J. Peiroten, P. Chartrin, A.J. Acher, Environ. Sci. Technol. 34 (2000) 34743479 . 


\section{TABLES}

Table 1. Apparent surface area $\left(S_{\mathrm{BET}}\right)$, micropore volume $\left(V_{\text {micro }}\right)$, non-microporous surface area $\left(\mathrm{S}_{\text {meso }}\right)$ and $\mathrm{pH}$ at the point of zero charge $\left(\mathrm{pH}_{\mathrm{PZC}}\right)$ obtained for the graphene-based materials.

\begin{tabular}{ccccc}
\hline Sample & $\begin{array}{c}S_{\text {BET }} \\
\left(\mathrm{m}^{2} \mathrm{~g}^{-1}\right)\end{array}$ & $\begin{array}{c}V_{\text {micro }} \\
\left(\mathrm{cm}^{3} \mathrm{~g}^{-1}\right)\end{array}$ & $\begin{array}{c}S_{\text {meso }} \\
\left(\mathrm{m}^{2} \mathrm{~g}^{-1}\right)\end{array}$ & $\begin{array}{c}\mathrm{pH} \\
\text { PZC }\end{array}$ \\
\hline GO & 23 & $\sim 0$ & 23 & 2.8 \\
rGOG & 94 & 0.004 & 90 & 5.2 \\
rGOH & 413 & 0.039 & 329 & 5.5 \\
rGOV & 29 & $\sim 0$ & 29 & 5.1 \\
\hline
\end{tabular}

Table 2. Intensity ratios of the D bands relative to the G mode for the rGO samples [23].

\begin{tabular}{ccc}
\cline { 2 - 3 } & \multicolumn{2}{c}{$I_{\mathrm{D}} / I_{\mathrm{G}}$} \\
\cline { 2 - 3 } & $514.5 \mathrm{~nm}$ & $785 \mathrm{~nm}$ \\
\hline $\mathrm{rGOG}$ & 1.85 & 4.00 \\
$\mathrm{rGOH}$ & 2.50 & 4.58 \\
$\mathrm{rGOV}$ & 2.16 & 4.26 \\
\hline
\end{tabular}

Table 3. Total amounts of $\mathrm{CO}_{2}$ and $\mathrm{CO}$ obtained from the TPD spectra of the graphene-based materials, and respective oxygen contents and $\mathrm{CO} / \mathrm{CO}_{2}$ ratios. In the case of the rGO samples, data obtained after CWPO are also given.

\begin{tabular}{ccccc}
\hline Sample & $\begin{array}{c}\mathrm{CO}_{2} \\
\left(\mu \mathrm{mol} \mathrm{g}{ }^{-1}\right)\end{array}$ & $\begin{array}{c}\mathrm{CO} \\
\left(\mu \mathrm{mol} \mathrm{g}{ }^{-1}\right)\end{array}$ & $\begin{array}{c}\mathrm{O}_{2} \\
(\%)\end{array}$ & $\mathrm{CO} / \mathrm{CO}_{2}$ \\
\hline GO & 5305 & 4156 & 23.6 & 0.8 \\
rGOG & 1056 & 1517 & 5.8 & 1.5 \\
$\mathrm{rGOG}_{\text {After CWPO }}$ & 8550 & 3612 & 32.1 & 1.0 \\
rGOH & 957 & 1872 & 6.1 & 2.0 \\
$\mathrm{rGOH}_{\text {After CWPO }}$ & 3457 & 4362 & 18.0 & 0.7 \\
$\mathrm{rGOV}$ & 1215 & 1328 & 6.0 & 1.1 \\
$\mathrm{rGOV}_{\text {After CWPO }}$ & 4776 & 4761 & 22.9 & 1.0 \\
\hline
\end{tabular}




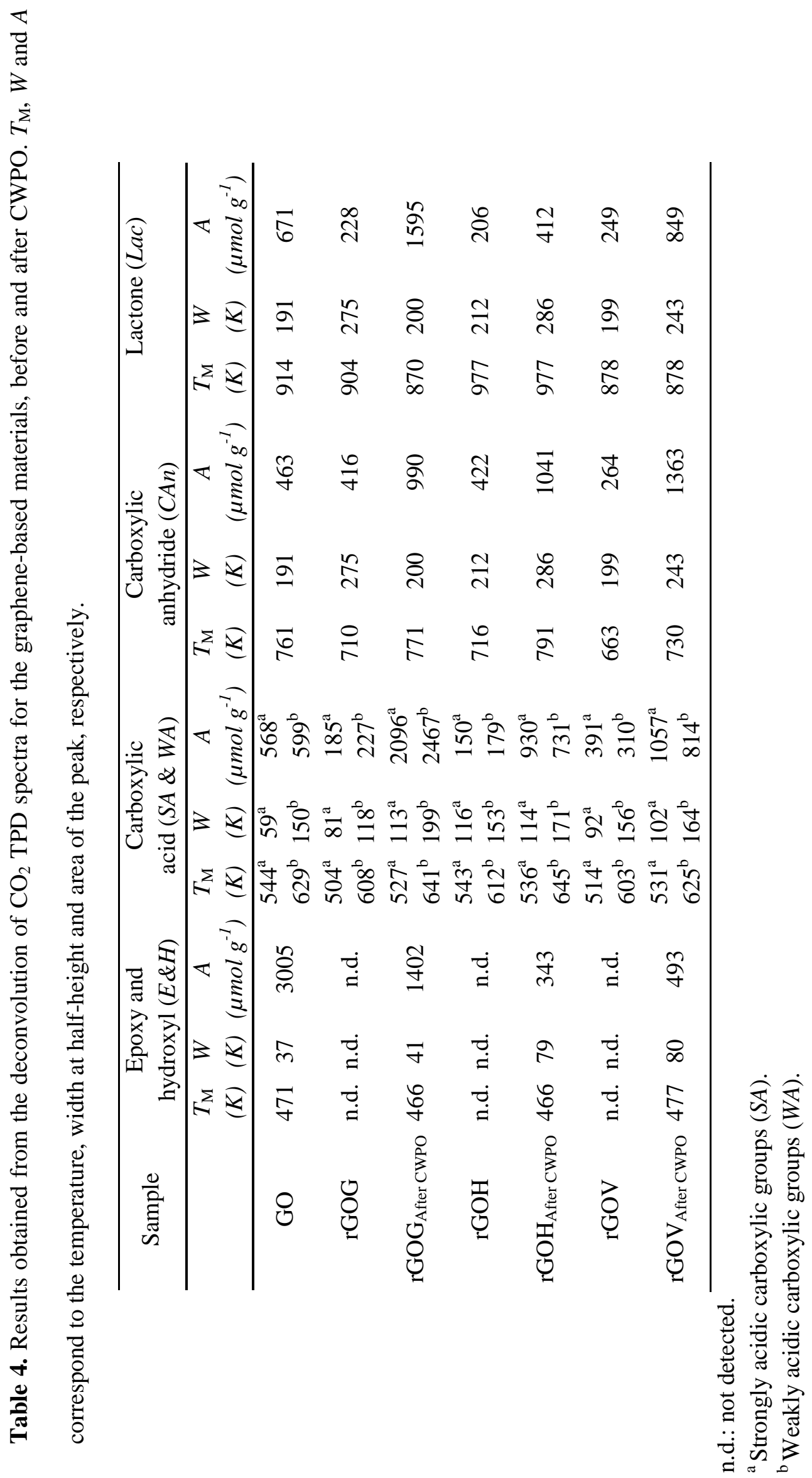




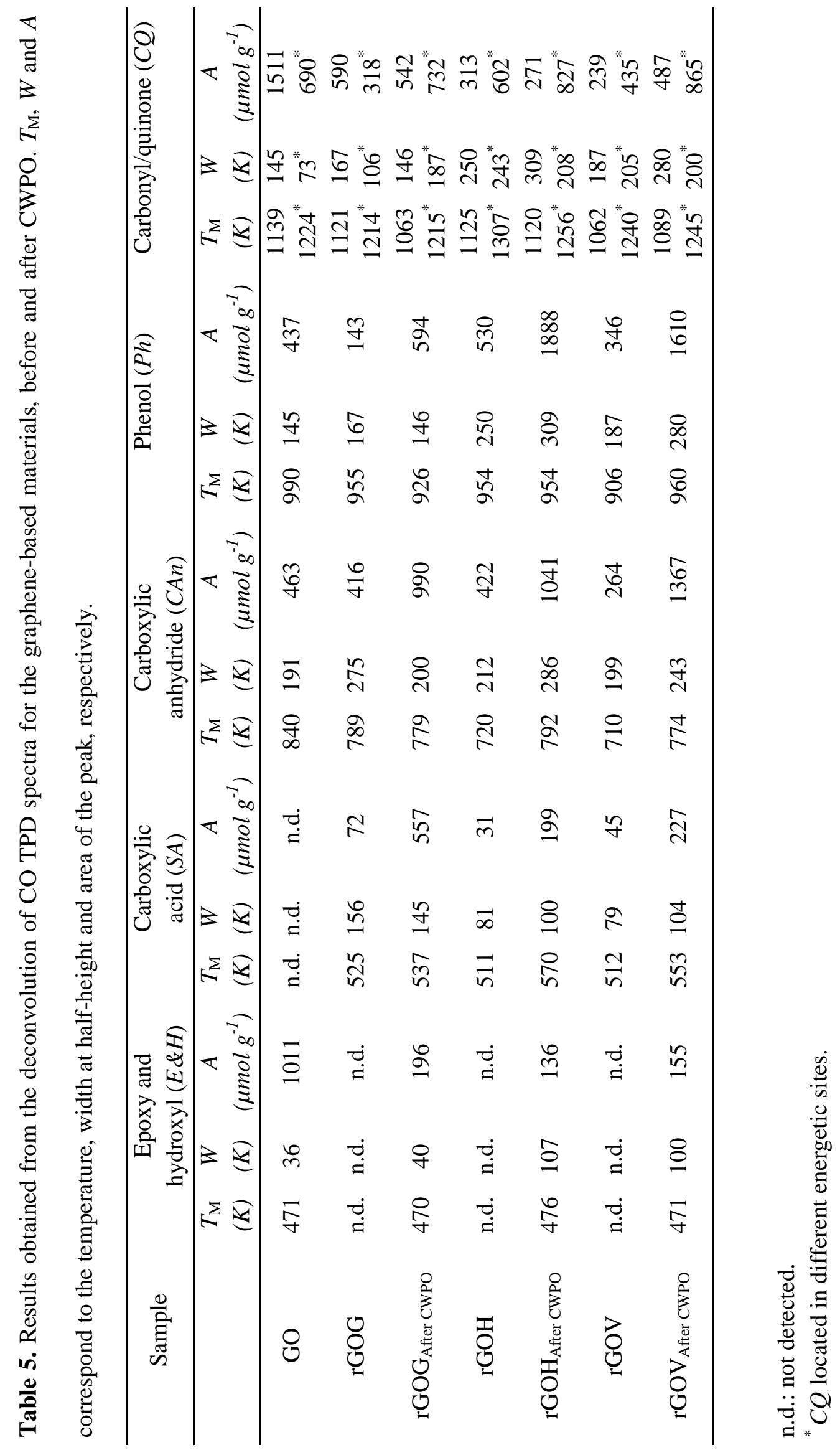




\section{FIGURE CAPTIONS}

Figure 1. $\mathrm{N}_{2}$ adsorption-desorption isotherms at $77 \mathrm{~K}$ of the graphene-based materials.

Figure 2. Deconvolution of TPD profiles for (a, b) rGOG, (c, d) rGOH and (e, f) rGOV, before and after CWPO; (a, c, e) $\mathrm{CO}_{2}$ profiles and (b, d, f) $\mathrm{CO}$ profiles. Nomenclature: $(E \& H)$ Epoxy and hydroxyl groups, $(S A)$ strongly and $(W A)$ weakly acidic carboxylic groups; $(C A n)$ carboxylic anhydrides; $(\mathrm{Lac})$ lactones; $(\mathrm{Ph})$ phenols; $(\mathrm{CQ})$ carbonyls/quinones.

Figure 3. Removal of 4-NP $\left(5.0 \mathrm{~g} \mathrm{~L}^{-1}\right)$ obtained in CWPO runs performed with the graphene-based materials $\left(2.5 \mathrm{~g} \mathrm{~L} \mathrm{~L}^{-1}\right)$, considering $T=323 \mathrm{~K}, \mathrm{pH}=3$ and $\left[\mathrm{H}_{2} \mathrm{O}_{2}\right]_{0}=\left[\mathrm{H}_{2} \mathrm{O}_{2}\right]_{\text {Stoichiometric }}=17.8 \mathrm{~g} \mathrm{~L}^{-1}$. Non-catalytic (blank) results are also shown for comparison.

Figure 4. 4-NP removal in adsorption and CWPO runs (bars/left axis) after $24 \mathrm{~h}$, and respective difference in the 4-NP percent removal between CWPO and pure adsorption experiments $\left[d_{\text {Removal }}\right.$ (squares/right axis)]. Non-catalytic (blank) results are also shown for comparison.

Figure 5. TOC removal per unit of $\mathrm{H}_{2} \mathrm{O}_{2}$ decomposed $\left(n_{\mathrm{H}_{2} \mathrm{O}_{2}}=\frac{x_{\mathrm{Toc}}}{x_{\mathrm{H}_{2} \mathrm{C}_{2}}}\right)$ vs. intensity ratios of the $\mathrm{D}$ bands relative to the $\mathrm{G}$ mode $\left(I_{\mathrm{D}} / I_{\mathrm{G}}\right)$ for the $\mathrm{rGO}$ samples. Points represent experimental data, while line represents the linear fitting.

Figure 6. 4-NP, $\mathrm{H}_{2} \mathrm{O}_{2}$ and TOC conversions obtained in a series of three consecutive CWPO runs performed with the rGO samples during $24 \mathrm{~h}$ (bars/left axis), and respective TOC removal per unit of $\mathrm{H}_{2} \mathrm{O}_{2}$ decomposed ( $\eta_{\mathrm{H}_{2} \mathrm{O}_{2}}$, squares/right axis).

Figure 7. Evolution of aromatic (a) and non-aromatic (b) by-products of 4-NP oxidation, when using rGOV in the CWPO process developed under the experimental conditions of Figure .

Figure 8. Proposed mechanism for the CWPO of 4-NP. 


\section{FIGURE 1}
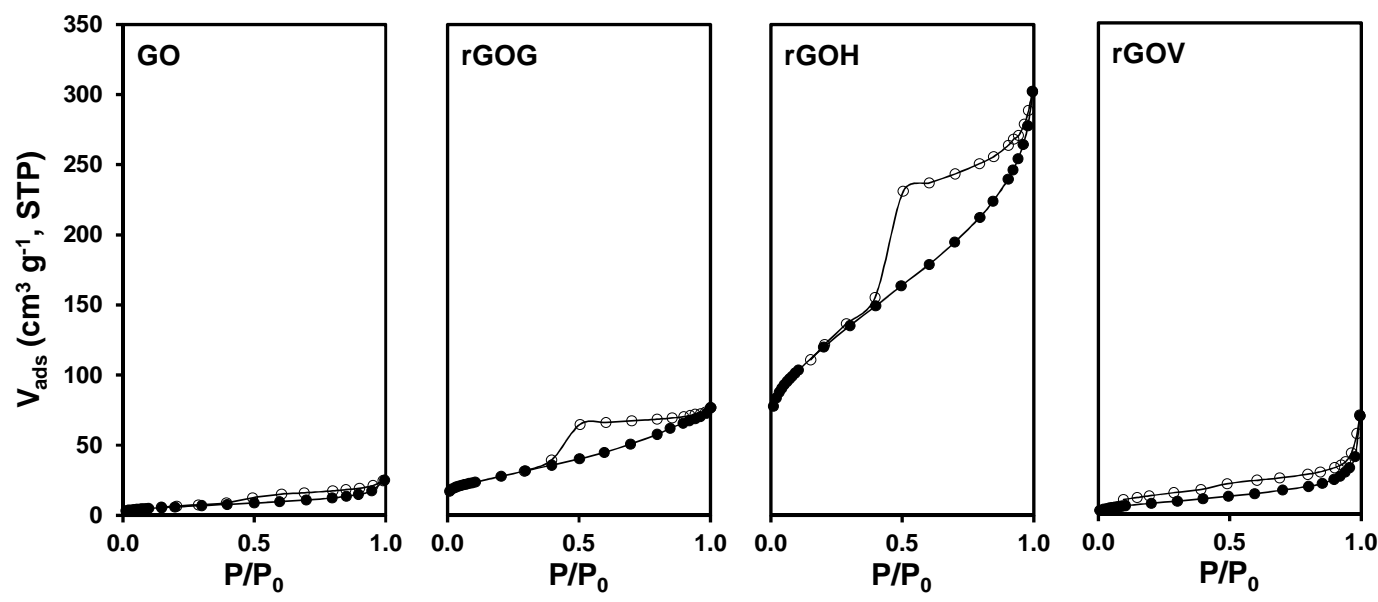
FIGURE 2
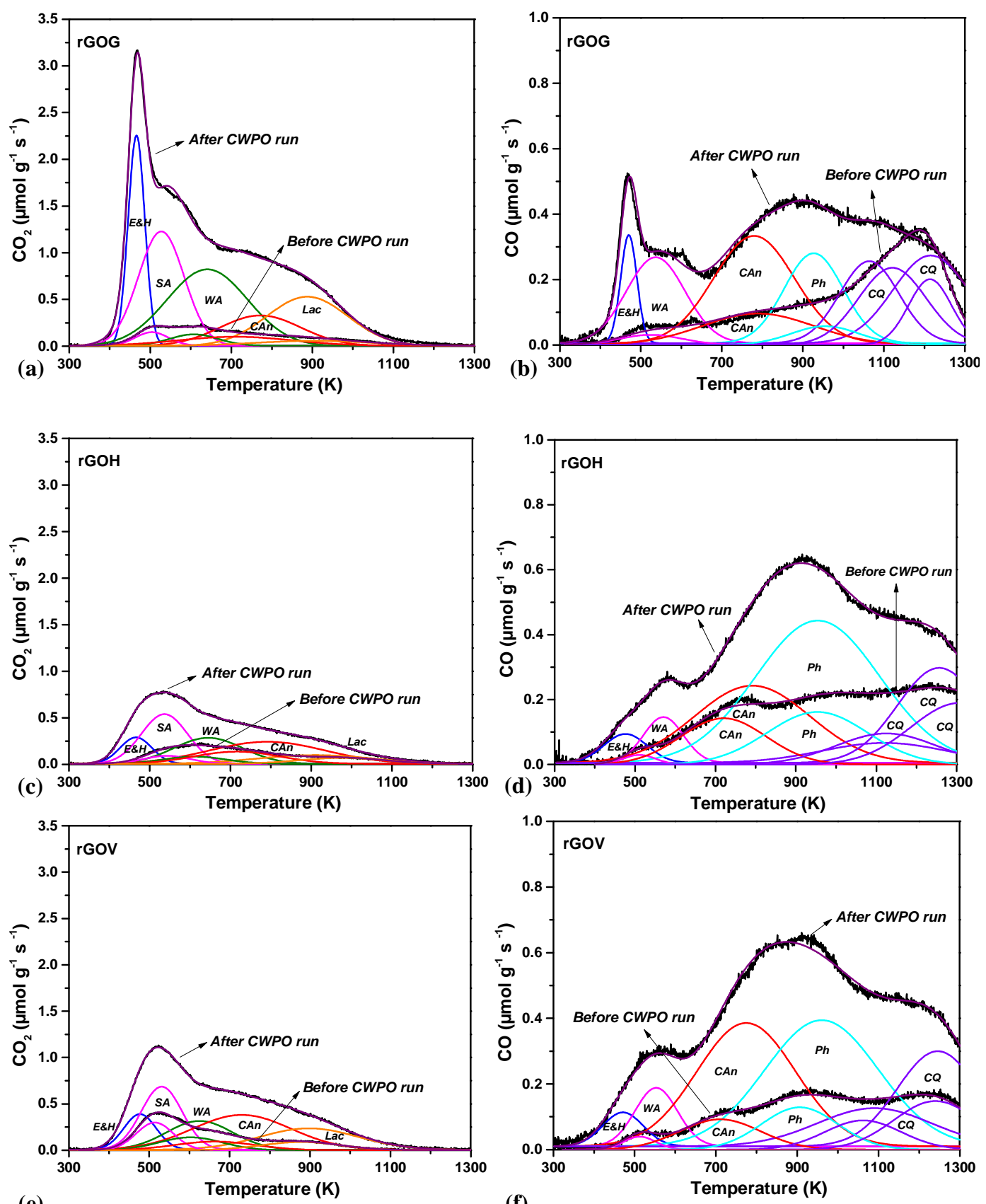

(f) 


\section{FIGURE 3}

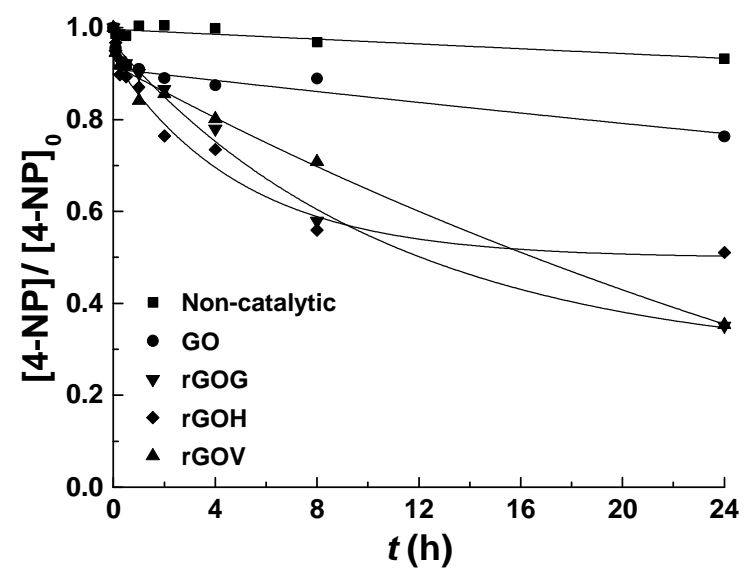




\section{FIGURE 4}

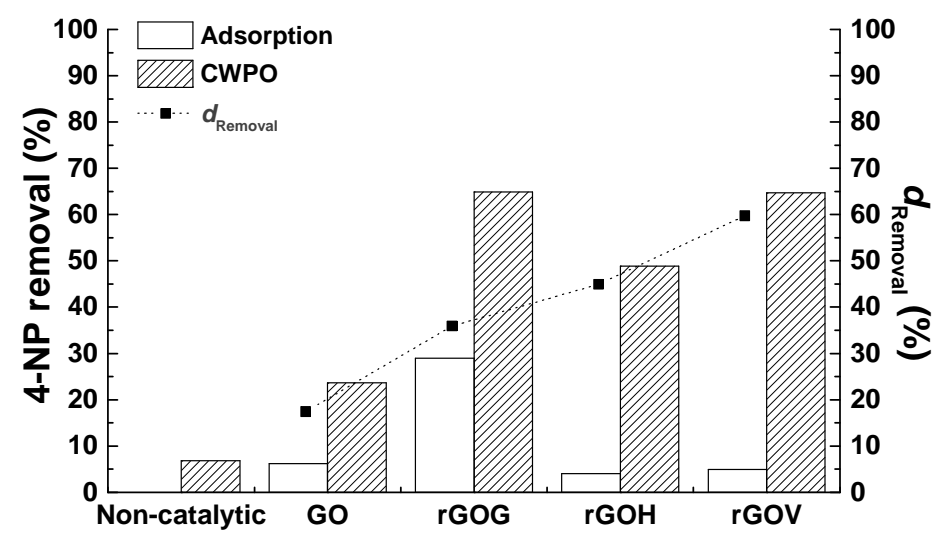




\section{FIGURE 5}

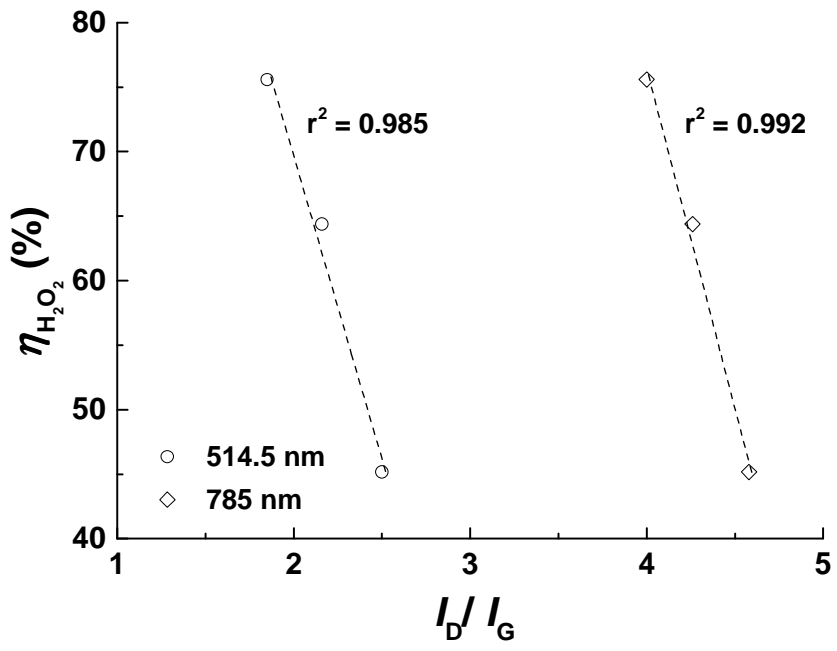


FIGURE 6

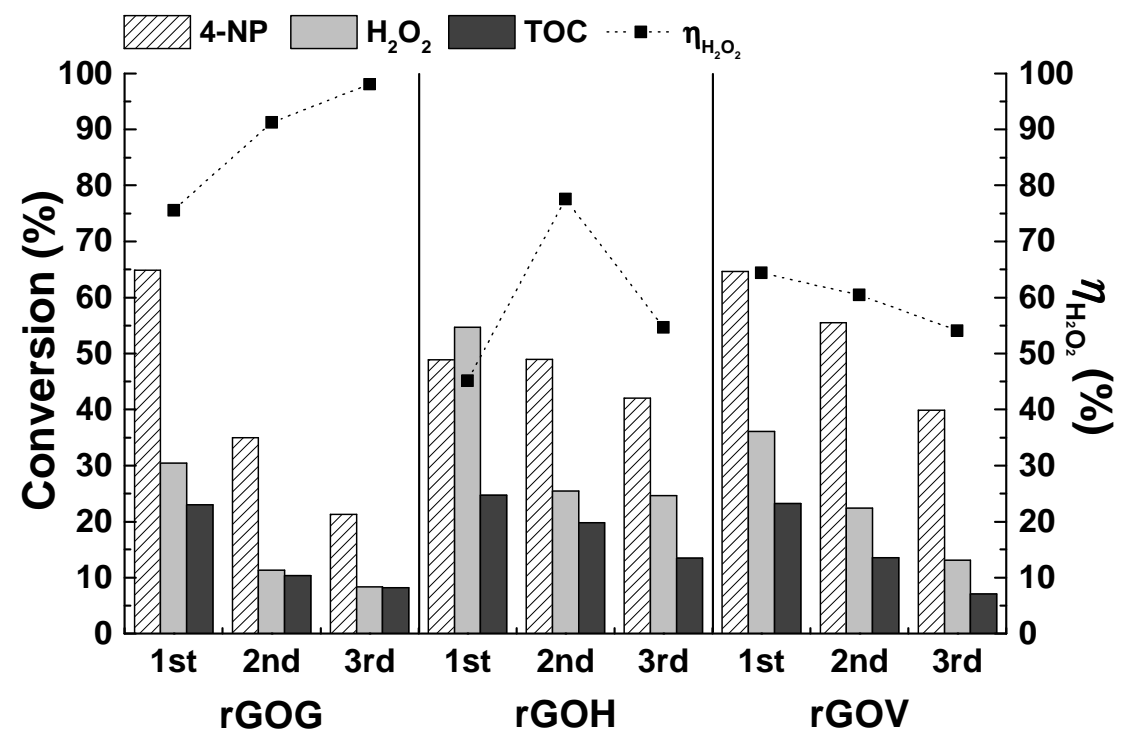


FIGURE 7
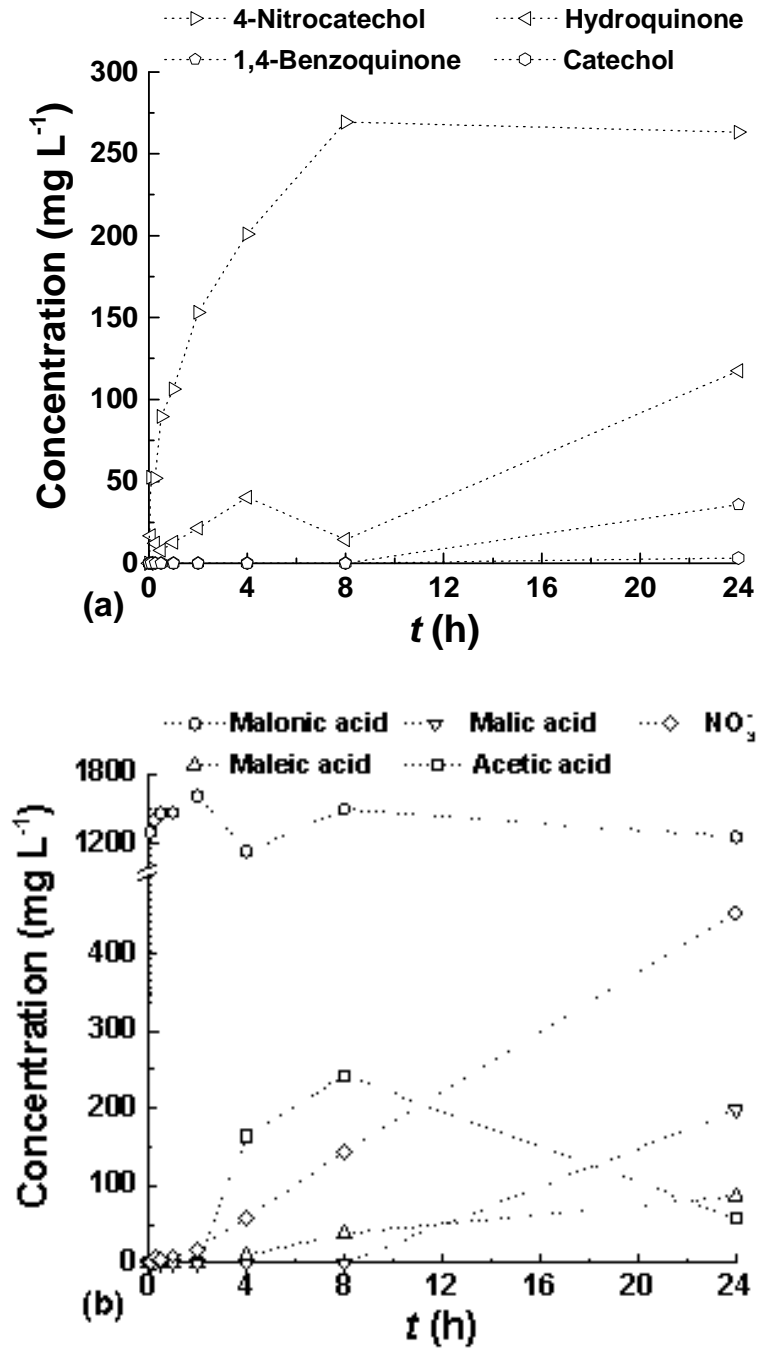


\section{FIGURE 8}

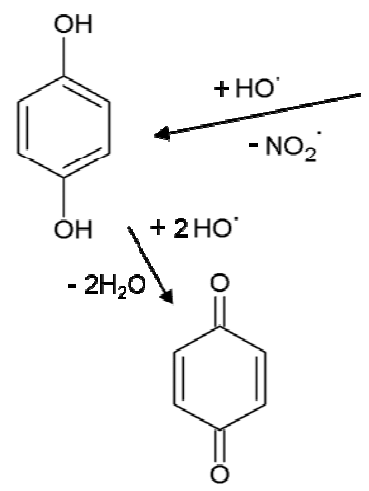

(NO

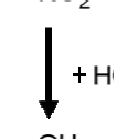

$+\mathrm{HO}$<smiles>Oc1ccccc1</smiles><smiles>Oc1ccccc1O</smiles>

$\downarrow+\mathrm{HO}^{\circ}$

$/+\mathrm{HO}^{\circ}$

Ring opening products<smiles>O=C(O)CC(=O)O</smiles><smiles>O=C(O)CC(O)C(=O)O</smiles><smiles>O=C(O)C=CC(=O)O</smiles><smiles>CC(=O)O</smiles>

$\downarrow+\mathrm{HO}^{\circ}$

$\mathrm{CO}_{2}+\mathrm{H}_{2} \mathrm{O}$ 
